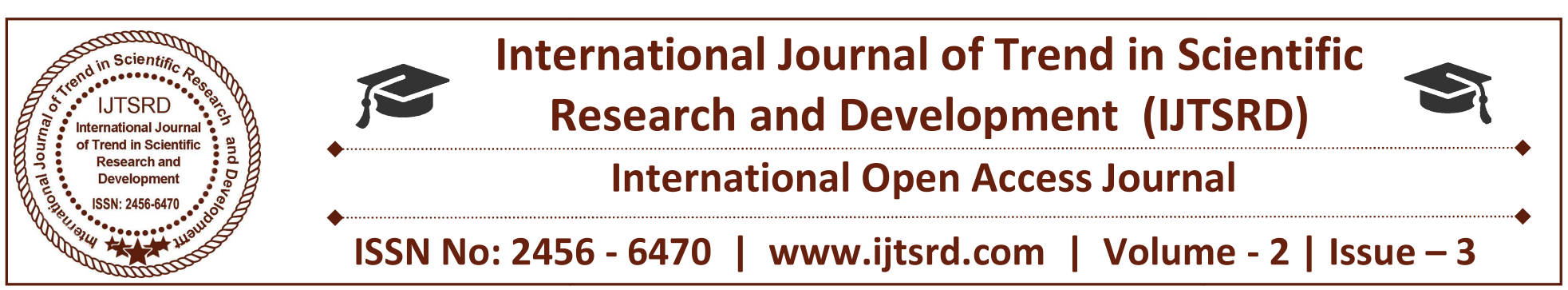

\title{
Exigency Response System with Location Trailing under IoT structure
}

\author{
${ }^{1}$ Kajal R. K Pandey, ${ }^{2}$ Ketan Arwat, ${ }^{3}$ Ishaan Sharma, ${ }^{4}$ Prof. Sonali Patil \\ ${ }^{4}$ M.E. (Computer Engineering) LMISTE, Assistant Professor and Head \\ 1,2,3,4 Department of Computer Engineering, Suman Ramesh Tulsiani Technical Campus, \\ Faculty of Engineering, SPPU Kamshet, Pune, Maharashtra, India
}

\begin{abstract}
During medical crisis, sometimes victims are unable to give information regarding their health and identification. Without any clue or enough data, doctors cannot identify victims and also cannot perform any medical treatment without their medical history. For such kind of situations, a system or a device which can provide the doctors about the victim's personal information and medical history can be very useful. This system can be described as an IOT based assistant which not only provides personal identification but also detailed information about emergency contacts, medical history and all past treatments. It also ensures to inform emergency contacts such as friends and families about victim's condition. Also emergency contacts can track any individual with the help of software application and hardware infrastructure, which is beneficial for all children and old people.
\end{abstract}

Keywords: GPS device, Identification, IOT ,Medical crisis, Security, Tracker

\section{INTRODUCTION:}

The Internet of Things (IoT) is a system of interrelation between computing system or device, mechanical system and digital communication and infrastructure, objects of given class, interface between system which are provided with a unique objects or parameters and also the techniques to transfer data over a given communication network without requiring any human-to-human or human to computer interaction.
The Internet of Things is redefining the system of healthcare as we learn about it daily. We're moving rapidly on to a whole new level of advancement when it comes to the way that nowadays apps, given devices and people interact when delivering healthcare solutions. IoT has given us a fresh outlook to the healthcare system as unique tools that can accommodate an integrated and combined healthcare network system, concurrently the care that is provided is of a higher standard. With the help of such kind of technology in healthcare methodology, there is an increase in prospect to improve the quality and efficiency of progressive treatments and simultaneously to help improve the health of the patients.

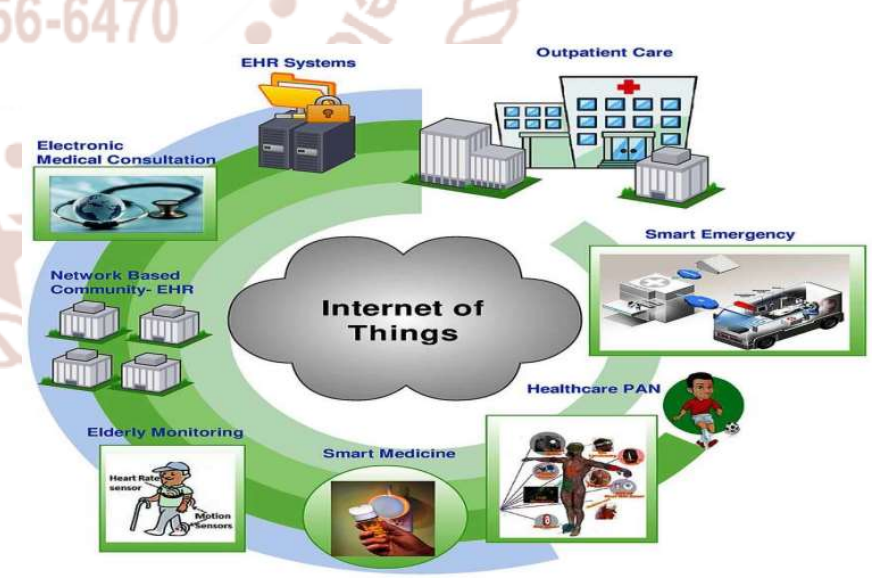

Fig 1: IOT in healthcare system

In the paper, an exact representation of a system which is useful for elderly as well as young adults and children. This system follows a method where one can track their family members even though not being present with that person at that time. A 
hardware device is provided as not all age group of user can use a mobile application in their day to day life.

\section{Internet of things and related work:}

The rapidly increased use of technology like mobile devices and smart devices in the area of healthcare system has caused massive impact on the world. Doctors and scientists are massively taking benefits of the advantages such kind of technologies, thus generating a significant and turbulent improvement in health care system not only in clinical settings but also out of them.

IOT system in Medical healthcare was started since usage of RFID tags to get identification of doctors and patients admitted in that hospital increased. A big question mark for security of doctor working in that hospital and patient admitted occurred which led to RFID tags. This was a start and a limit at that time for IOT occurrence in the system. This system was defined as object service prototyping. Then came usage of security in M-health that is medical health which uses security features provided by cyber security similar reason which occured first that is for identification. This gradually increase need of safety laid to another system that is RFID indoor location awareness for patients inside hospital campus. This was basically a simulation program for corporate health facilities for patient.

Such kind of inventory helped in building a IOT infrastructure in healthcare which led to creating a system for patients with different and specific diseases and so on. A future in IOT infrastructure in healthcare is vast maybe more that we can imagine. Such kind of system generation led us to our prototype of personal identification of victims with a emergency group of people providing not only medical history of that people but also a track and alert feature for safety and security of users.

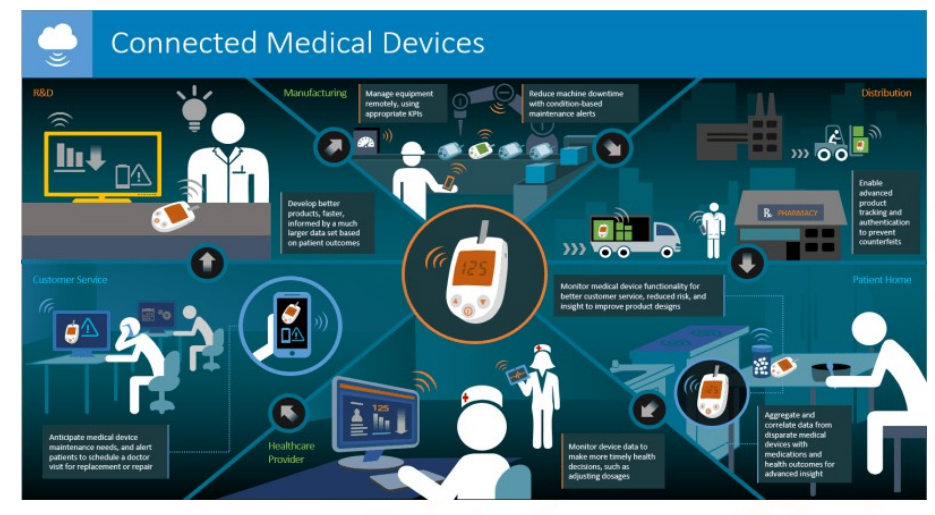

Fig 2: IOT in medical devices

\section{III.Prototype System Implementation:}

The given system is software application provided with hardware infrastructure with a unique identification to every user, basic medical data and emergency contact numbers will be provided to registered users with a permission to add members to distinguish between tracker and trackee. In the time of any medical emergency like accidents or physical health $\bigcirc$ issues, the registered person will get immediate medical treatment or help once a alert is generated and received by the emergency number listed by user and detailed medical history will be provided immediately to the hospital being approached at that instance.

Along with the GPS device, a interconnected mobile application that will be available to accessible to all the user account and which will manage the members coming under that particular account as well as a feature of updating the medical history of all the members. This GPS device is a type of GPS navigation device which is simply a GPS receiver, or a GPS device which is capable of receiving information about the user from GPS satellites and then to calculate the device's geographical position and then resend to the person tracking the system. All it needs is a GSM sim card especially a nano sim card with registered number of user and a direct interconnection with the mobile application with registered user account. This mobile application provides user a way to track any member associated to the user account without their help which only requires slipping in the GPS device and then to get not only historic route data of that member but also current location and activity. An emergency feature in case of a sudden need is provided to send assigned 
contacts an alert with the help of mobile application and GPS device. The GPS tracking device registeres a limited area range of traversal from user for trackee so that when the trackee go outside the area a SOS alert with location is send to User.

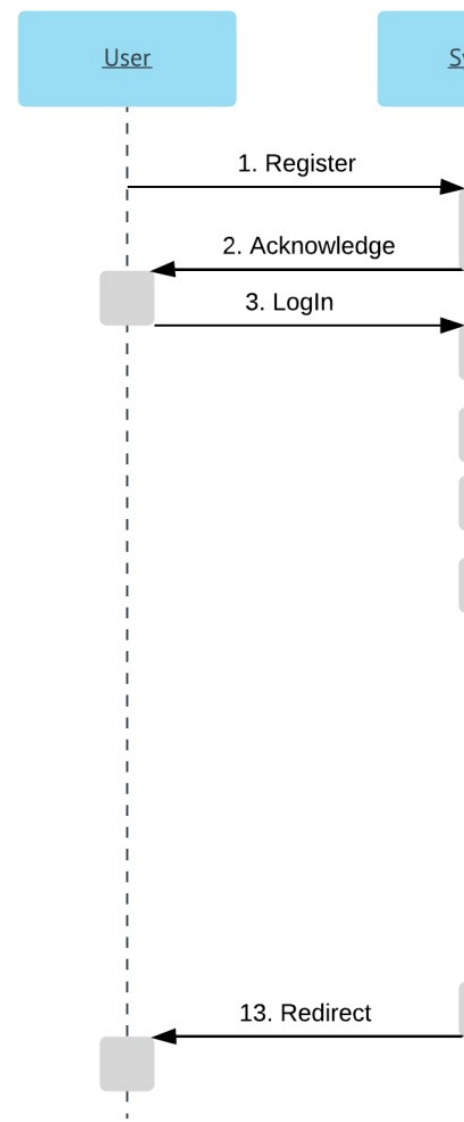

\section{Application:}

\section{Medically challenged people}

Now a days, awareness regarding people who suffer with autism, mental illness also physical disability has increased. Even though this people who are no less different than normal people still requires a assistant to get through from this busy life created by technology itself. Also families of such special of kind of people have a continuous worry about their whereabouts creating big question marks on their life as independent citizen. With such kind of system they can be at ease with the surroundings these people work in by continuously keeping a track of it without them knowing about these.

\section{Elderly people}

Since elder people do not have a proper eyesight restrain also physical weakness provided by their age increase, this system provides their respective and authorized guardians to keep a tab on them and ensure their safety.

\section{Children}

Children are the beings which are a carefree age of normal human being. But this does not changes the fact that their are behind them worried about their whereabouts which such kind of system provides a assurity.

\section{Medical Centers}

Centers build for medical emergencies can take benefits from this system to keep a track of their patients once admitted. 
International Journal of Trend in Scientific Research and Development (IJTSRD) ISSN: 2456-6470

\section{School organization}

Such kind of system can help school authority track their whereabouts without tailing every student on the campus.

\section{Conclusion:}

This system which uses Internet of things can be beneficial and also can be used as an alternative for elderly as well as children safety in emergency. Likewise with this set of solutions, can also be used to increase quality of safety of users and not only for monitoring them. In order to ensure the required privacy and security of user and all members, a separate device is used with a direct interconnection to system provided to user. Not only, it is tracking mechanism system but also a it stores medical information of the members added in that system. This helps in all the other procedure which occurs after a victim is classified and also immediately after a accident or medical emergency with the help of alert feature in the system as well as hardware.

The internet of things has a huge amount of countless of applications in healthcare system that is not only beneficial to patients, families but also doctors, physicians and so on. There are few hospitals that are using the internet of things infrastructure in healthcare system even to keep the tiniest patients safe, sound and healthy, while others are using the technology to start keeping a track of their inventory.

\section{REFERENCES:}

1. Jorge Gomeza, Byron Oviedo, Emilio Zhuma La Universidad de Córdoba, Departamento de Ingeniería de Sistemas, Montería- Colombia b Universidad Técnica Estatal de Quevedo, Facultad de Ciencias de la Ingeniería, Quevedo - Ecuador ,'Patient Monitoring System Based on Internet of Things " The 7th International Conference on Ambient Systems, Networks and Technologies (ANT 2016) , Procedia Computer Science 83 ( 2016 ) 90 - 97 ,Elsevier

2. Alexandre Santos, Joaquim Macedo, António Costa , M. Joao Nicolaus ,'Internet of Things and Smart Objects for M-Health Monitoring and Control Procedia Technology", CENTERIS 2014 - Conference on Enterprise Information Systems /
ProjMAN 2014 - International Conference on Project MANagement / HCIST 2014 International Conference on Health and Social Care Information Systems and Technologies 16 ( 2014 ) 1351 - 1360 , Elsevier

3. S. M. Riazul Islam, (Member, IEEE), Daehan Kwak, MD. Humaun Kabir, Mahmud Hossain, And Kyung-Sup Kwak, (Member, IEEE) "The Internet of Things for Health Care: A Comprehensive Survey" 2015.2437951 VOLUME 3,2015

4. Luca Catarinucci, Danilo De Donno, Luca Mainetti, Luca Palano, Luigi Patrono, Maria Laura Stefanizzi, and Luciano Tarricone "An IoT related Architecture for Smart Health Care Systems" 2327-4662 2015 IEEE

5. K. Natarajan UG Scholar/Nandha Engineering College/ Erode/ Tamil/Nadu/ India B. Prasanth UGScholar/Nandha Engineering College/ Erode/ Tamil Nadu/ India P. Kokila Assistant Professor/ECE/Nandha Engineering College/ Erode/ Tamil Nadu// India "Smart Health Care System Using Internet of Things" Volume 6, I JNCET, issue 3, 2016 March

6. Punit Gupta, Deepika Agrawal, Jasmeet Chhabra, Pulkit Kumar Dhir Jaypee University of Information Technology Himachal Pradesh, India "IoT based Smart HealthCare Kit" ICCTICT.2016.7514585 March 2016

7. M. Akiyama and R. Nagai, "Information technology in health care: E-health for Japanese health services,' A Report of the CSIS Global Health policy center, The Center for Strategic and International Studies and the Health and Global Policy Institute, Mar. 2012. [Online]. Available:http://csis.org/files/publication/120327 Akiyama_JapaneseHealthCare_web.pdf, accessed Dec. 27, 2014.

8. K. A. Stroetmann, J. Artmann, and V. N. Stroetmann, "e-health strategies-European countries on their journey towards national ehealth infrastructures,' Information Society, European Commission, Jan.2011.[Online]. Available:http://ehealth- 
International Journal of Trend in Scientific Research and Development (IJTSRD) ISSN: 2456-6470 strategies.eu/report/eHealth_Strategies_Final_Rep ort_Web.pdf, accessed Dec. 27, 2014

9. R. S. H. Istepanian and Y.-T. Zhang, "Guest editorial introduction to the special section: $4 \mathrm{G}$ health-The long-term evolution of m-health," IEEE Trans. Inf. Tech.Biomed., vol. 16, no. 1, pp. 1-5, Jan. 2012

10. Ranjeet Kumar, Rajat Maheshwari, Amit Aggarwal, M. Shanmugasund School of Electronics Engineering, VIT University, Vellore, Tamil Nadu, Indiaaram and Sundar S.'IOT BASED HEALTH MONITORING SYSTEM USING ANDROID APP" ARPN Journal of Engineering and Applied Sciences VOL. 12, NO. 19, OCTOBER 2017

11. International Journal of Innovative Research in Computer and Communication Engineering "An IOT Based Health Care Monitoring" System-A Review Sneha N. Malokar 1,Samadhan D. Mali 2 Department of Electronics and Telecommunication, Sinhagad College of Engineering, Vadgaon, BK, Pune, India ,Vol. 5, Issue 6, June 2017

12. IEEE International Conference on Services Computing "Health Monitoring and Management Using Internet-of-Things (IoT) Sensing with Cloud-based Processing: Opportunities and Challenges" Moeen Hassanalieragh, Alex Page, Tolga Soyata, Gaurav

13. Sharma, Mehmet Aktas, Gonzalo Mateos Burak Kantarci , Silvana Andreescu of ECE,URMC University of Rochester Rochester, NY 14627 of ECE, Chem BioM Sci Clarkson University Postdam, NY 13699 